\title{
On the Promotion and Sustainable Development of Chinese Teaching in West Africa-Taking Benin National University for Instance
}

\author{
Liang $X u^{1}$, Yixue Luo ${ }^{2^{*}}$ \\ ${ }^{1}$ Foreign Language School, Neijiang Normal University, Neijiang Sichuan, 641112, China \\ ${ }^{2}$ School of Overseas Education, Sichuan University, Chengdu, 610064, China \\ *Corresponding author
}

Keywords: West Africa, Chinese, Education, Current situation, Strategies

\begin{abstract}
According to the survey, recently, in the universities of West Africa, there is no university facilitated with Major of Chinese and constructed Chinese curriculum system. Moreover, few researchers have ever done research on West African countries' Chinese education. Benin National University is the supreme university in Benin. The author once was the Chinese teacher working there sponsored by the Chinese government during 2009 and 2012. Based on the 16 years' Chinese education history and the current situation, this article put forward the corresponding way of promotion and sustainable development for the Chinese teaching there, hoping to take it a sample for West African Chinese promotion and development.
\end{abstract}

\section{Introduction}

In today's international spread of Chinese culture, the Chinese international promotion because of different national conditions and showing a trend of diversification, country studies and country-specific development for the Chinese region has become increasingly urgent and necessary. Ongoing national, regional expansion is also limited to Chinese language teaching research carried out earlier in the United States and Europe as well as Asia's traditional Chinese cultural circle, and for the study of Chinese teaching in Africa on fewer, for the majority of West and Central Africa countries, Chinese promotion situation, yet nobody cares. For the current situation of Chinese teaching the less developed regions such development in the above (such as teaching methods used, teaching mode, teaching materials, etc. are adapted to the realities of the local economy, political background, education system, etc.), little comprehensive research.

Located in West Africa, known as the "national culture among the top West African" countries Benin, since 1972 and since China resumed diplomatic relations, the "Chinese fever", "Chinese Culture Fever" will continue to heat up. Chinese Teaching in 1996 from the National University of Benin officially launched, but no one has ever been associated with their research. Based on the international promotion of Chinese strategic context, this article has focused on the history of Chinese teaching and promotion of the National University of Benin, the status of the investigation carried out a comb and a comprehensive analysis of the survey results and proposed for the sustainable promotion of Chinese language teaching Benin and solving ideas and feasibility of the proposed development, in a bid by a summary of the Chinese model of development of the National University of Benin, generalizations and innovation, so that Benin experience can provide other West African countries and even the less developed areas of language teaching and research for sustainable development provide a reference for the basis, so as to promote the country's Chinese international "soft power" and public diplomacy strategic initiatives to make a modest contribution.

\section{Evolution and status of Chinese teaching in Benin National University}

\section{Introduction of Benin National University}

Benin National University, Benin's only a relatively perfect teaching equipment comprehensive university, is more famous institutions of higher learning in West Africa, more than 50,000 current students. It is under the jurisdiction of 17 universities and research institutions; and the school is also 
the Head of State of Benin and the industry leader's birthplace, the previous minister and the president of Benin ministries have graduated from the school.

\section{Evolution of Chinese teaching in Benin National University and analysis}

Chinese as a foreign language lesson National University of Benin electives, since October 1996, Chinese State Education Commission sent the first Chinese language teachers from the National University of Benin. From 1996 to 2009, there have been six national public school Chinese language teachers to teach in Benin, for a term of two to three years. Each year the number of Chinese teachers is held at three.

Now respectively, from the two main Chinese Teaching subjects in National University of Benin History and current situation of teaching Humanities Institute and the Confucius Institute are described below:

\section{Chinese course status in Humanities Institute}

School of Humanities, National University of Benin is the school's largest college, covering more comprehensive humanities and social sciences disciplines, the number of students in reading 10,000 people. 1996 National University offers Chinese language courses since Chinese is designed for English Major College of Humanities and Linguistics Majors II outside elective, other students cannot elective. Chinese teachers are national public school teacher, teaching hardware is able to accommodate 300 people two large classrooms, no multimedia, and other auxiliary teaching facilities.

Curriculum Provision

A. "Chinese Getting Started": Teaching object of freshman English majors, Place into the main campus and Porto-Novo campus, the annual total hours to 34 hours, materials for "Contemporary Chinese" the first book (1st).

B. "Elementary Chinese": Teaching object English sophomore, Place into the main campus and Porto-Novo campus, the annual total hours to 34 hours, materials for "Contemporary Chinese" the first book (2nd).

Overview for the number of students select Chinese over years

The school year the number of students learning Chinese rise, according to statistics, in 1996 Chinese students to 45, and then to double the number of annual growth, up to 2011, the number of Chinese students has reached 1735 people. It can be seen students taking Chinese enthusiasm and demand is very high. At the same time, increase the number of language courses far beyond the requirements, reducing the learning.

Existing problems

Firstly, students' professional background is single. Its participants in non-English majors from the University of Abomey-Calavi students accounted for 70\%, the specialty, including French, law, natural sciences.

Secondly, the teaching conditions greatly restrict the conduct of language teaching. Due to limitations of the classroom, teaching quality has been greatly affected. And the number of students impact on teaching. Because class size is too large, teacher-student interaction can only use the main student group practice, reducing the number of participants is imperative.

\subsubsection{Chinese course in Confucius Institute}

Confucius Institute of Bénin National University was established in Mar. 25, 2009, the goal is to open for the various disciplines of Chinese students curricula and dissemination of Chinese culture.

(1) Hardware conditions. Currently teaching Chinese Confucius Institute has two classrooms, multi-media equipment and more than 3,000 sets of books Profile

(2) Situation of students. Since 2013 before the Confucius Institute courses and credits not included in the school system, so the course can only be based amateur interest groups, while at a Scheduling time must take into account the needs of individual students, students have been seriously affected.

(3) Curriculum provision status of Curriculum Provision 
Confucius Institute courses currently still running stage, the curriculum is: 1. Chinese Beginners: Using the textbook "Contemporary Chinese" the first book, 48 hours; 2. senior class: Textbooks "Contemporary Chinese" Book 48 hours, place both Confucius Institute classrooms.

\section{Analysis on Goals and needs of Chinese teaching in National University of Benin}

\section{Elective questionnaire for Chinese as a second language students learning Chinese}

\section{Survey}

In this survey, the survey objects for the National University of Benin University of Porto Novo Campus and all first-year and two campuses sophomore trainees.

\subsubsection{Survey tools}

This survey uses "National University of Benin Chinese Elective Course Students Questionnaire" (French version), to understand and investigate only for student learning objectives. Answer time is 15 minutes, questions mainly five dimensions of objective multiple-choice questions.

Investigative steps

The use of sampling questionnaires, select the row were four classes of normal course recess issued by the instructor on-site, on-site voluntarily fill and recovered. The survey total of 1000 questionnaires distributed, 766 recovered, the recovery rate was $76.6 \%$, received a total of 567 valid questionnaires, the effective rate was $74.4 \%$.

Attached table Student learning objectives statistics of Benin National University

\begin{tabular}{|c|c|c|c|c|c|}
\hline & Fully agree & Agree & Not sure & Disagree & $\begin{array}{l}\text { Totally } \\
\text { disagree }\end{array}$ \\
\hline 1.Ready to go to study in China & $11.8 \%$ & $10.3 \%$ & $77.9 \%$ & 0 & 0 \\
\hline 2. To find a little better job & 0 & $13.8 \%$ & $65.8 \%$ & $10.4 \%$ & 0 \\
\hline 3. In order to obtain credits & $77.9 \%$ & $10.3 \%$ & $11.8 \%$ & 0 & 0 \\
\hline 4. To meet the needs of the unit & 0 & 0 & $100 \%$ & 0 & 0 \\
\hline $\begin{array}{l}\text { 5. To satisfy their interest in Chinese } \\
\text { culture and Chinese }\end{array}$ & 0 & $36 \%$ & $44 \%$ & $20 \%$ & 0 \\
\hline 6. To meet the needs of parents & 0 & 0 & $22.8 \%$ & $65.8 \%$ & $21.4 \%$ \\
\hline 7. To facilitate tourism in China & $10 \%$ & $13.3 \%$ & $43.3 \%$ & $20 \%$ & $13.4 \%$ \\
\hline $\begin{array}{l}\text { 8. Facilitate the exchange of know more } \\
\text { Chinese-speaking friends }\end{array}$ & 0 & $44.1 \%$ & $44.1 \%$ & $11.8 \%$ & 0 \\
\hline $\begin{array}{l}\text { 9. Easy to enjoy Chinese TV movie } \\
\text { songs }\end{array}$ & $11.8 \%$ & $44.1 \%$ & $44.1 \%$ & 0 & 0 \\
\hline $\begin{array}{l}\text { 10. Easy to understand the Chinese } \\
\text { people's life }\end{array}$ & $24 \%$ & $54.1 \%$ & $11.9 \%$ & 0 & 0 \\
\hline $\begin{array}{l}\text { 11. Want to make themselves look more } \\
\text { education and experience }\end{array}$ & 0 & $44.1 \%$ & $44.1 \%$ & $11.8 \%$ & 0 \\
\hline 12. Meet their self-esteem & 0 & $22.1 \%$ & $22.1 \%$ & $55.8 \%$ & 0 \\
\hline $\begin{array}{l}\text { 13. Explore new knowledge to meet } \\
\text { their own needs }\end{array}$ & $33.8 \%$ & $44.1 \%$ & $22.1 \%$ & 0 & 0 \\
\hline 14. Self-worth & 0 & $33.2 \%$ & $33.2 \%$ & $33.6 \%$ & 0 \\
\hline $\begin{array}{l}\text { 15. Make their own thinking and doing } \\
\text { things the same as the Chinese people }\end{array}$ & 0 & $10.3 \%$ & $33.9 \%$ & $22.1 \%$ & $33.7 \%$ \\
\hline
\end{tabular}

Survey results and data analysis

According to surveys and statistics, 95 percent of students for Chinese learning is very positive, but more than $30 \%$ of students for Chinese class learning objectives are not clear; $2 \%$ of students do not even know what is the meaning of elective Chinese language; "To credit and learn "reached 80\%. This shows that a student is to "mixed credits" and elective. Some students holding a fresh approach to learning to play, and this kind of attitude is precisely the direct impact on the classroom schedule and teaching quality. 


\section{Thoughts and Suggestions of Chinese teaching and promotion in National University of Benin}

\section{Course reform}

Since the Confucius Institute at the brand around the world and their own strength, so the Chinese language teaching unified under the umbrella of the Confucius Institute at National University of Benin, can take advantage of the Confucius Institute of the international brand, and increase efforts to train students and influence. Curriculum reform as follows:

\section{Chinese major course:}

This course is in accordance with China's domestic Chinese language courses combined with Benin local facts set aim is to incorporate Chinese professional higher education system of the country, training for local development needs of professional Chinese talent. 2. The curriculum can be taught in class type, such as: Chinese Intensive Reading (beginner, intermediate, advanced), I heard classes (beginner, intermediate, advanced), and other professional courses, the creation of elective courses, teaching time arranged according to the school's teaching time. 3. Admissions way: According to the results of the university entrance exam merit, and Chinese oral interview. 4. Enrollment: 30 people. 5. Instructor: public school teachers and teachers of the Confucius Institute. Chinese training course:

This course is for the Benin social admissions Chinese short-term training courses, the main object for the beginners student teaching or learning the basic Chinese students a year, according to Chinese students were divided into beginner, intermediate and advanced three levels in their spare time Chinese training: creation of Chinese Intensive (elementary, intermediate and senior classes), Chinese heard (elementary, intermediate, advanced courses), professional Chinese (senior class), Chinese Reading and Writing (Intermediate, advanced Class), etc. .

Chinese optional course:

This course is intended for all professional school students offering Chinese as a foreign language elective, with basic Chinese conversation, understand the Chinese culture as the main learning content. 1. Course Title: "Chinese Basics", the same junior class content and language training courses. 2. Session: According to the unified arrangement university teaching time, academic year. 3. Use the textbook: "Contemporary Chinese first book." 4. Instructor: public school teachers and teachers of the Confucius Institute.

Above curriculum reform can be established for the National University of Benin Teaching Chinese a complete system including Chinese professional training courses in Chinese, Chinese elective courses.

\section{Policy support of Benin government}

Although Chinese teaching Benin has been carried out for many years, learning Chinese is raising year by year the number of people eager to learn more Chinese to understand Chinese. Chinese government has done a lot of efforts to establish a cultural center in China and the Confucius Institute for Chinese language training based on the two bases from the actual action.

\section{Construction of hardware facilities}

Benin is one of the world's most developed countries, investment in education compared to most countries in the world still at a very low level. In this case, the Confucius Institute at National University of Benin can take advantage of its strong financial advantage to build own comprehensive teaching and multimedia facilities, in order to promote the rapid development of Chinese teaching and promote Chinese culture.

\section{Construction of teaching staff}

The number of electives from Chinese statistics can be found, the shortage of Chinese language teachers need to be alleviated as soon as possible. A public school teacher and two teachers of the Confucius Institute has been completely unable to meet the needs of schools, teaching Chinese domestic needs additional volunteers in order to solve the shortage of teachers in the short-term problem. Do early preparations for the comprehensive development of Chinese teaching.

\section{Set Chinese classroom in middle and primary school}

Primary and secondary schools during the critical period of language learning in primary and secondary schools offer Chinese language classes to improve students' interest in learning, reducing 
Chinese fear of hardship, to enable students to more easily master the Chinese language law, to lay the foundation for the university to continue their studies.

Develop Chinese teaching materials suitable for Benin

"After market testing is the fundamental teaching, teachers to stay away from the body, foreigners living close to textbooks, teaching organization", whether it is the initial "Learning Chinese", "Chinese language course" is now "Contemporary Chinese", which write and teach object or a foundation is more focused on students in developed countries, France, Canada, where many scenes not suitable for the local social situation and there are a lot of Benin outdated expression.

\section{Working closely with the Chinese Culture Center in Berlin}

Berlin Chinese Cultural Centre is to support the Chinese Government and the Government of Benin in, driven at September 27, 1988 was established, whose main task is to spread the Chinese culture and support of the entire African culture, in particular the promotion of cultural undertakings and Benin exchange and development.

\section{Conclusions}

"Culture is not spread like gunboats; the battle will be played, also unlike the Industrial Revolution immediate results. Therefore cultural communicator must be ascetic." And for the most underdeveloped areas of West Africa, the Chinese language education should how to go, what experience, you need to study how, all we need to work harder to explore and discover.

We hope this report will give the proposed feasibility Benin - West Africa - Chinese Teaching in Africa provides a reference basis, but will study the authors continue, from a more micro perspective to explore the development of West Africa and even the Chinese in Benin road.

\section{Acknowledgments}

The study was sponsored by Neijiang Normal University 2012 annual university research project "Development Mode of Chinese Teaching in Benin". Project number: 12NJS20

\section{References}

[1] Introduction of Bénin National University(French edition), 2004.

[2] Confucius Institute of Bénin National University introductory course and advanced course curriculum provision(trial), 2009

[3] Introduction of Confucius Institute of Bénin National University, http : // college. chinese.cn /conference09 /article /2009-12 / 29 /content_98166. htm, 2009.

[4] Constitution of Confucius Institute, NOCFL Confucius Institute website: http: // college. chinese.cn /article/ 2009-08/25/content_12541.htm, 2009.

[5] Xu Liang, Benin Chinese culture center Chinese-teaching analysis and future development model, Journal of Guizhou Normal College, 2010. 2.

[6] Xu Lin, Soft promotion of Chinese language culture: http : // news. Xinhuanet. Com /politics/ 2008-05/ 06 / content_8113032.htm

[7] Zhang Hongming, Nations - Benin, front introduction, 2004: 295.

[8] Zhong Yinghua, Some basic issues in the construction of Africa Confucius Institute, Jounral of Yunnan Normal University, 2009.1. 